\title{
CORRECTION
}

\section{Correction to: In vitro mechanistic studies on a-amanitin and its putative antidotes}

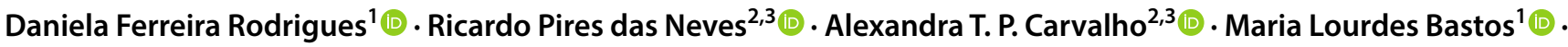 \\ Vera M. Costa ${ }^{1}$ (i) Félix Carvalho $^{1}$ (])
}

Published online: 17 April 2020

(c) Springer-Verlag GmbH Germany, part of Springer Nature 2020

\section{Correction to: Archives of Toxicology \\ https://doi.org/10.1007/s00204-020-02718-1}

In the original publication of the article, Fig. 1 has been published with an error. The scale which is in black and white should be in red color.

The correct Fig. 1 is given in this correction.

The original article has been updated.

The original article can be found online at https://doi.org/10.1007/ s00204-020-02718-1.

Vera M. Costa

veramcosta@ff.up.pt

$\triangle$ Félix Carvalho

felixdc@ff.up.pt

1 UCIBIO, REQUIMTE, Laboratory of Toxicology, Faculty of Pharmacy, University of Porto, Rua Jorge Viterbo Ferreira, 228, 4050-313 Porto, Portugal

2 UC-Biotech, CNC - Center for Neuroscience and Cell Biology, University of Coimbra, 3060-197 Cantanhede, Portugal

3 Institute for Interdisciplinary Research, University of Coimbra, 3030-789 Coimbra, Portugal 
A

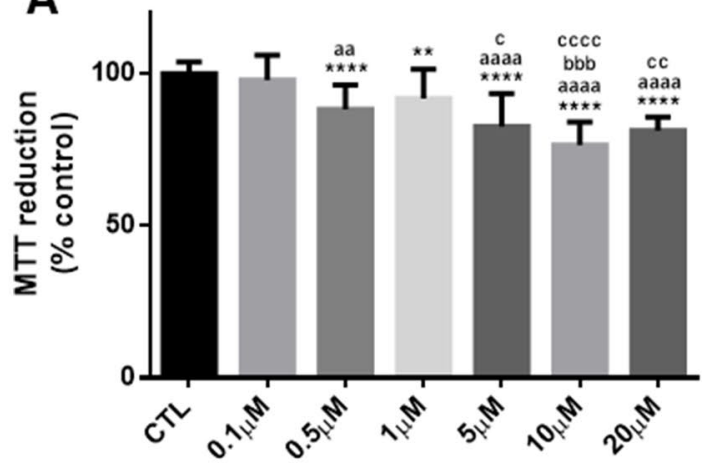

C

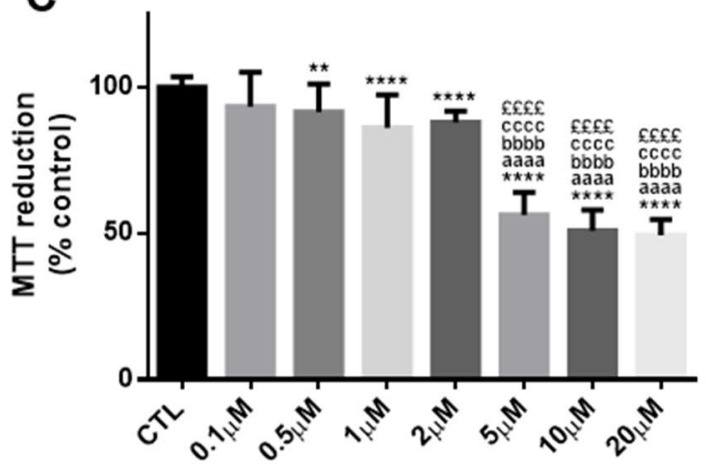

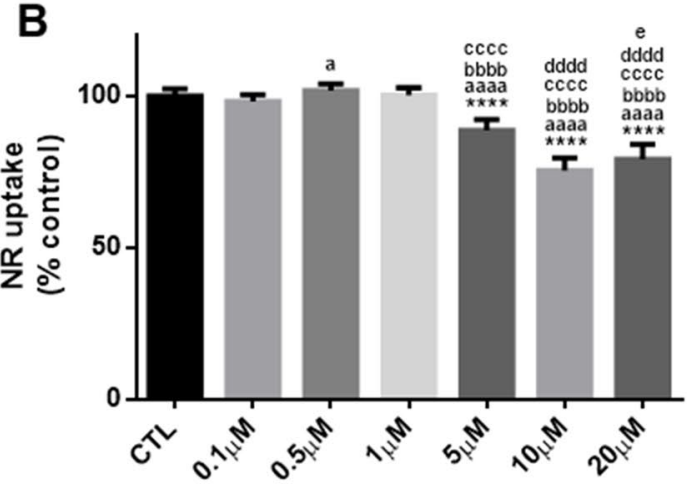

D

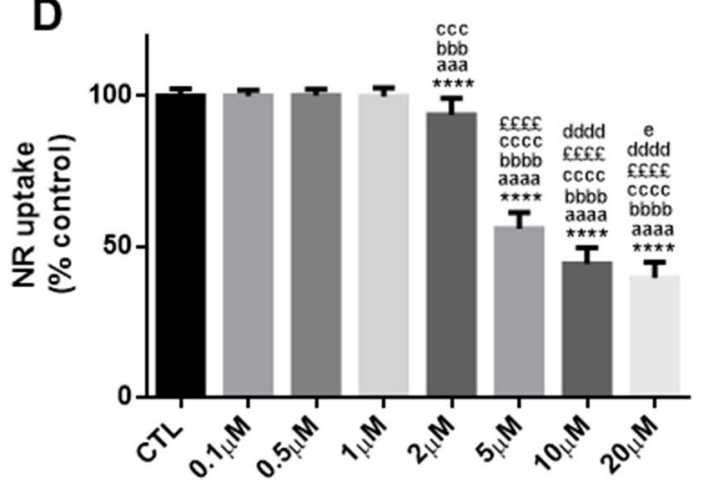

E

Control
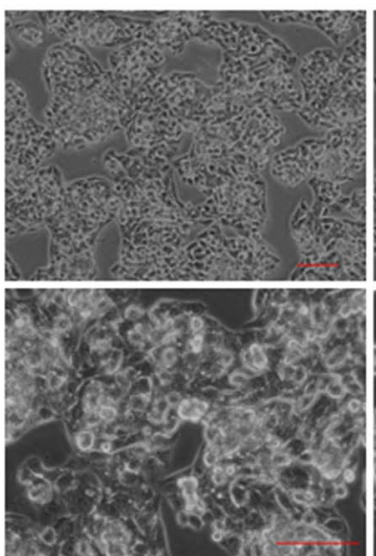

AMA $5 \mu M$
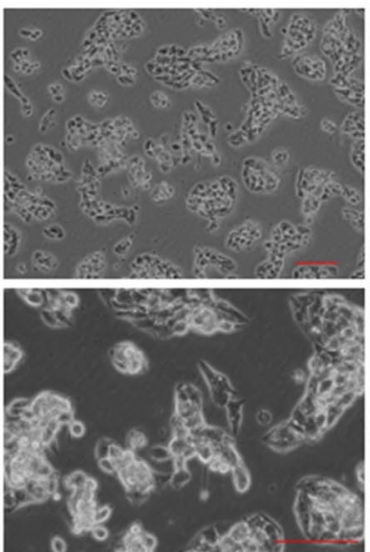

AMA $10 \mu M$

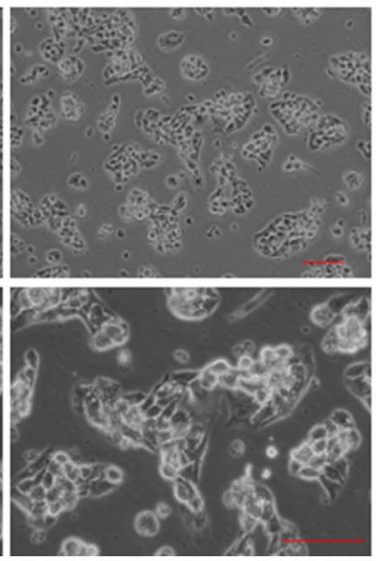

AMA $20 \mu M$

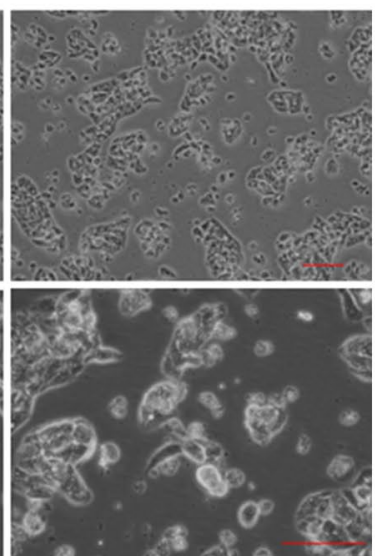

Publisher's Note Springer Nature remains neutral with regard to jurisdictional claims in published maps and institutional affiliations. 